\title{
Aerosol Delivery to a Critically Ill Patient: A Big Issue Easily Solved by Developing Guidelines
}

\author{
Mohamed E. A. Abdelrahim
}

Received: July 12, 2018 / Published online: July 31, 2018

(C) The Author(s) 2018

\section{ABSTRACT}

Nowadays, therapeutic aerosols are commonly delivered to mechanically ventilated patients by nebulizers and pressurized metered dose inhaler attached to an adapter or a spacer. Studies with asthmatics and chronic obstructive pulmonary disease patients have confirmed that aerosol delivery during mechanical ventilation is feasible. They have also reported that the inhaled drugs administered during mechanical ventilation provide greater and faster clinical outcomes than when delivering during spontaneous unassisted breathing. Researchers studied factors that would affect aerosol delivery during mechanical ventilation. Even with the tremendous amount of publications in this area, there have still been no recommendations or guidelines released to help respiratory therapists in their decision as to when to deliver aerosol to ventilated patients. Mostly,

Enhanced digital content To view enhanced digital content for this article go to https://doi.org/10.6084/ m9.figshare.6850055.

M. E. A. Abdelrahim ( $₫)$

Clinical Pharmacy Department, Faculty of

Pharmacy, Beni-Suef University, Beni Suef, Egypt

e-mail: mohamedemam9@yahoo.com

M. E. A. Abdelrahim

Clinical Pharmacy Department, Faculty of

Pharmacy, Modern University for Technology and Information, Cairo, Egypt respiratory therapists read the literature and decide accordingly what to do and which device to use for their patients. This puts the patients at risk of receiving a sub-therapeutic or toxic dose of the inhaled aerosol. Some studies raise an alarm of physician decision upon reading any released publication related to aerosol delivery in mechanical ventilation without a trusted recommendation and guidelines. This increases the need for the development of recommendations and guidelines, by a trusted board or society, for aerosol delivery to such critically ill patients. To summarize, inhaled drugs administered to critically ill patients is of benefit compared to taking the patient off the ventilator and delivering during spontaneous unassisted breathing. However, dependable guidelines are needed to optimize aerosol delivery.

Keywords: Fill volume; HFNC; Humidification; Non-invasive ventilation; pMDI; Spacer; Ventilator setting; Vibrating mesh nebulizers

\section{INTRODUCTION}

Therapeutic aerosols are commonly administered to mechanically ventilated patients [1-4]. These agents are delivered by nebulizers [5-8] and a pressurized metered-dose inhaler (pMDI) 
attached to an adapter or spacer through ventilator circuits [6, 9-11].

Studies in patients with stable asthma [12] and chronic obstructive lung disease (COPD) [13] have confirmed that aerosol delivery during mechanical ventilation is feasible and provides great and fast clinical outcomes [7, 14].

Researchers have studied factors that would affect aerosol delivery during mechanical ventilation, e.g., aerosol generators, add-on devices, patient interfaces, patient-related factors, ventilator-related factors, and circuit-related factors $[9,10,13,15-26]$. They even studied the effect of the design of the nebulizer reservoir chamber on aerosol delivery [27] and fugitive aerosol effect on surrounding healthcare provider $[25,28]$.

Most of these studies concluded that aerosol delivery is much better when using a vibrating mesh nebulizer (VMN) in a dry non-humidified circuit $[18,19,29]$. The position of the nebulizer in the ventilation circuit varied according to the ventilation setting, type of ventilator, and ventilation circuit used.

When using a single-limb ventilation circuit, it is better to place the aerosol generator between the patients and the leak port as shown in Fig. $1[13,17]$, but when using a dual-limb ventilation circuit, it is better to place the aerosol generator in the inspiratory limb, as shown in Fig. $2[24,30]$ for better aerosol delivery.

Even with the tremendous amount of publications in this area, still no recommendations or guidelines have been released to help respiratory therapists in their decisions when delivering aerosol to ventilated patients.
Mostly, respiratory therapists read the literature and decide accordingly what to do and which device to use for their patients. This puts the patients at risk of receiving a sub-therapeutic or toxic dose of inhaled aerosol. The aim of the present mini-review is to show how important the development of guidelines for aerosol delivery to cortically ill patients is.

\section{EFFECT OF FILL VOLUME AND HUMIDITY ON AEROSOL DELIVERY}

An example of the need of such important guidelines is our last finding regarding the effect of fill volume of respiratory solution, placed in the nebulizer reservoir chamber, on delivered aerosol [25, 31, 32].

Similar to what has been found by many studies, we reported that increasing fill volume of respiratory solution placed in the nebulizer reservoir chamber by normal saline resulted in much higher aerosol when using a jet nebulizer, as shown in Fig. 3. However, increasing the fill volume had no significant effect when using VMN, as shown in Fig. 3. It even increased the nebulization time with no significant benefit $[25,31,32]$. So increasing the fill volume with saline is not beneficial for all types of nebulizers.

Another example of the need of such important guidelines was our new finding, which opposes all the previously published literature. Previous literature has suggested switching off the humidifier while delivering aerosol to ventilated patients to increase lung deposition $[18,19,29]$. This would let the

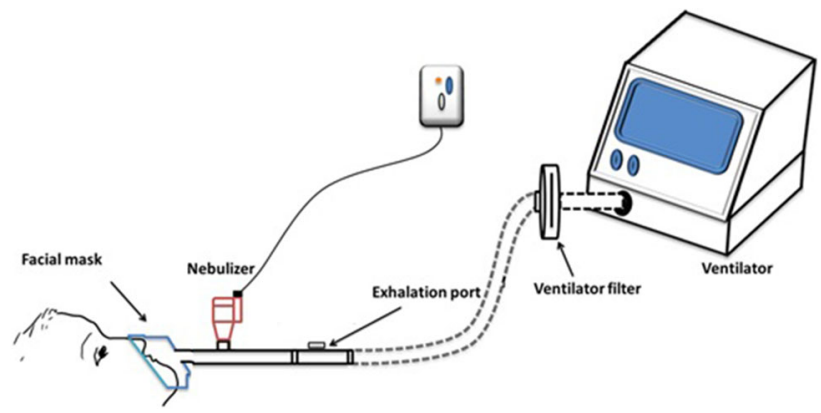

Fig. 1 Position of aerosol generator in the single-limb ventilation circuit [47] 


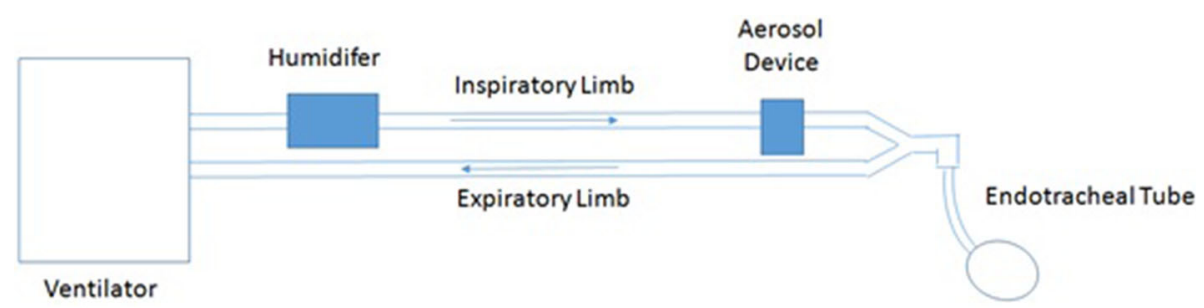

Patient

Fig. 2 Position of aerosol generator in dual-limb ventilation circuit [24]

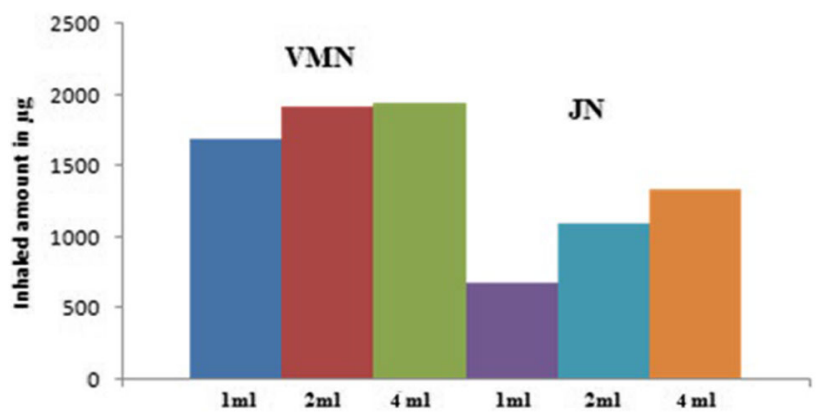

Fig. 3 Total aerosolized salbutamol in $\mu \mathrm{g}$, presented as mean, from $5000 \mu \mathrm{g}$ in 1,2 , and $4 \mathrm{ml}$ fill volumes $(n=10)[25]$

patient face the risk of inhaling dry gas, which has a harmful effect on the lungs [33]. These risks are even greater if the clinician fails to turn on the humidifier upon conclusion of aerosol administration.

We reported that there was no need to switch off the humidifier while delivering aerosol to the ventilated patient, as shown in Fig. 4 [25]. We verified our finding by studies using automatic continuous positive airway pressure (auto-CPAP) [26] and non-invasive single-limb [31, 32] and invasive dual-limb [30] ventilations and still found no significance between delivering aerosol in humid or dry circuits. Furthermore, we found no significant effect of switching off or on the humidifier on the clinical status of ventilated patients [24]. So, why put the patient at risk of receiving dry gas, while delivering aerosol, which might harm his or her lungs? In addition, it was previously

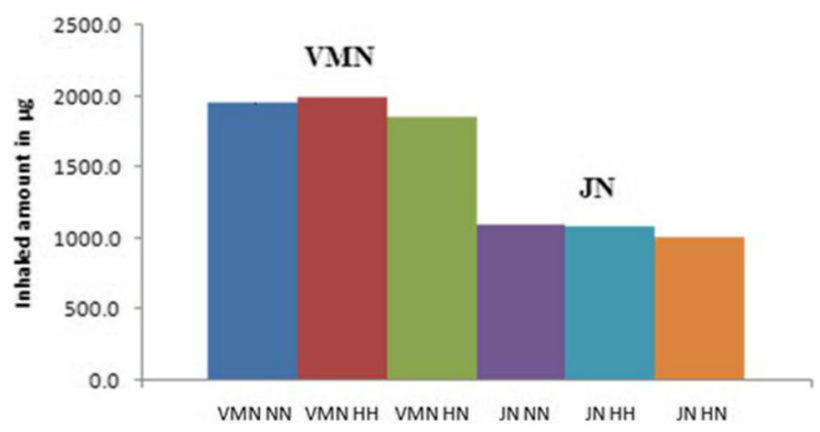

Fig. 4 Total aerosolized dose in $\mu$ g, presented in mean, with ambient, humidified, and heated humidity with JN and VMN $(n=10)$, no heat and no humidification (NN), humidification with no heat (HN), and heat with humidification $(\mathrm{HH})[25]$ 


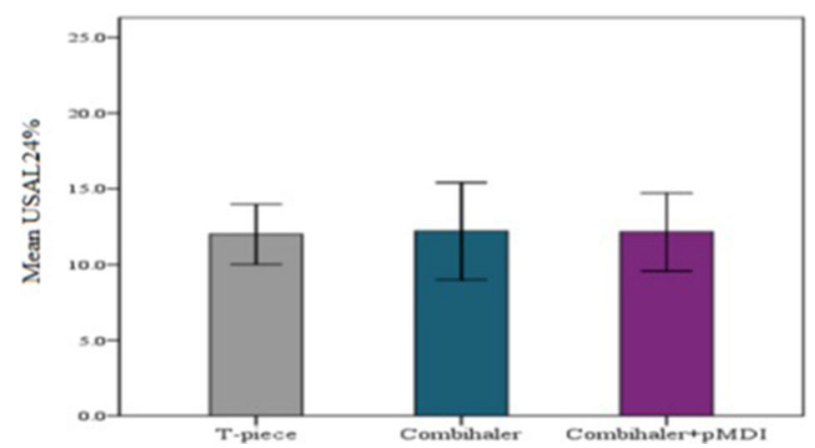

Fig. 5 Mean (SD) urinary excretion of salbutamol $24 \mathrm{~h}$ post inhalation of salbutamol respirable solution via vibrating mesh nebulizer through the three different connections expressed as percentage of nominal dose $(n=12)[48]$

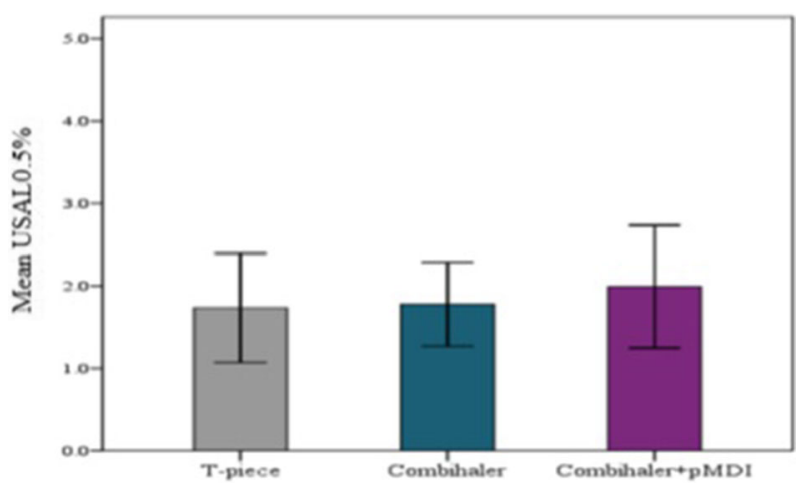

Fig. 6 Mean (SD) urinary excretion of salbutamol $30 \mathrm{~min}$ post inhalation of salbutamol respirable solution via vibrating mesh nebulizer through the three different connections expressed as percentage of nominal dose $(n=12)$ [48]

reported that the ventilation circuit will still contain humid air for more than 20 min after switching off the humidifier [34]. This was attributed to the patient exhaling humid air and the presence of condensation in the circuit that kept absolute humidity high despite reduced circuit temperature [34].

\section{THE USE OF SPACER WITH NEBULIZER}

A final example of the need for guidelines is a new add-on spacer called the Combihaler, which was designed for the use of a pMDI and nebulizer together in a ventilation circuit. The producer of this device claims that giving the patient one or two pMDI bronchodilator puffs before using the nebulizer increases aerosol delivery of the nebulized medication. They validated this in a dual-limb ventilation circuit while placing the spacer in an inspiratory limb [35]. However, in a single limb, we did not find any significant effects on the systemically absorbed aerosol, as shown in Fig. 5, but just a slight insignificant increase in lung deposition, as shown in Fig. 6 [36]. Additionally, the large volume of the spacer increased the dead volume inspired by the patient in the single-limb ventilation circuit [36].

These studies and others raise an alarm of physician decision upon reading any released publication related to aerosol delivery in mechanical ventilation without good trusted recommendations and guidelines. These recommendations and guidelines need to be developed by a trusted board or society for aerosol delivery to such critically ill patients. 


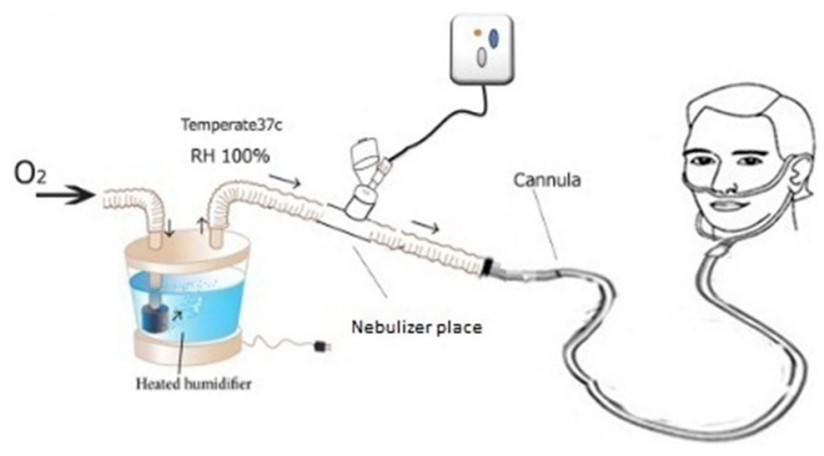

Fig. 7 Position of aerosol generators after the humidification chamber within high-flow nasal cannula oxygen therapy (HFNC) [46]

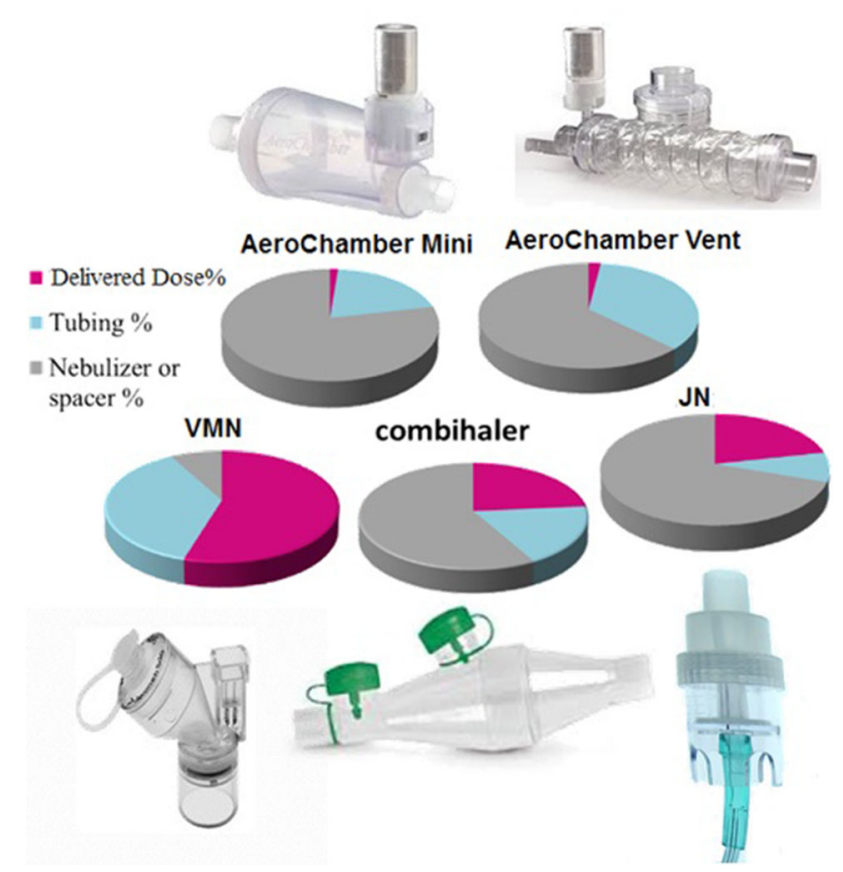

Fig. 8 Mean fate, in percentage, of the dose delivered using five different inhalation methods $(n=5)[46]$

\section{AEROSOL DELIVERY TO PATIENTS USING HIGH-FLOW NASAL CANNULA (HFNC)}

Another critically ill patient who would benefit from the delivery of aerosol is the patient using a high-flow nasal cannula (HFNC). In practice, the nasal cannula is the most popular tool used for providing critically ill patients with supplemental oxygen [37-40].
HFNC is better tolerated than the non-invasive ventilation with a mask and can provide a wide extent of oxygen concentrations as needed [41].

Recently, there has been a growing trend towards delivering aerosol medications using HFNC. The possibility of such therapeutic combination in a clinical setting is still argued.

Aerosol delivery through the nose is advantageous over oral inhalation, as it can improve both patient comfort and compliance by simply 
using a cannula to administer frequently dosing drugs and also drugs nebulized over long times [42].

The question arising here was how to combine aerosol delivery with the HFNC system and at the same time maximize aerosol delivery to the lungs. Previous bench studies, which evaluated combining aerosol delivery with an HFNC system, spotted that delivered dose was found to increase with decreasing gas flow rates and with wider-sized cannulas [43-45]. They also recommended placement of aerosol generators immediately after the humidification chamber within the circuit for better aerosol delivery, as shown in Fig. 7 [43-45].

We validated this by delivering aerosol to COPD patients using oxygen flow rate $(5 \mathrm{l} / \mathrm{min})$ in adult nasal-cannula to compare both the pulmonary and systemic bioavailability of different aerosol generators. Aerosol generators were placed immediately after the humidification chamber within the circuit [46].

We found that inhaled aerosols can be delivered efficiently at low oxygen flow using VMN and jet nebulizer in an HFNC system, while pMDIs with spacers deliver negligible amounts of drug below that expected for clinical response at this flow, as shown in Fig. 8 [46].

\section{CONCLUSIONS}

To summarize, inhaled drugs administered to critically ill patients during mechanical ventilation or HFNC is of benefit compared to taking the patient off the ventilator and delivering during spontaneous unassisted breathing. However, dependable guidelines are needed to optimize aerosol delivery.

\section{ACKNOWLEDGEMENTS}

Credit for this work and others must go to BeniSuef University Clinical pharmacy department young members who have done all the experimental work. Credit also must go to James B. Fink and Patricia Dailey. Without their help we would not have done any of this work.
Funding. No funding or sponsorship was received for this study or publication of this article.

Authorship. All named authors meet the International Committee of Medical Journal Editors (ICMJE) criteria for authorship for this article, take responsibility for the integrity of the work as a whole, and have given their approval for this version to be published.

Disclosures. Mohamed E. A. Abdelrahim has nothing to disclose.

Compliance with Ethics Guidelines. This article is based on previously conducted studies and does not contain any studies with human participants or animals performed by any of the authors.

Data Availability. Data sharing is not applicable to this article as no datasets were generated or analyzed during the current study.

Open Access. This article is distributed under the terms of the Creative Commons Attribution-NonCommercial 4.0 International License (http://creativecommons.org/licenses/ by-nc/4.0/), which permits any noncommercial use, distribution, and reproduction in any medium, provided you give appropriate credit to the original author(s) and the source, provide a link to the Creative Commons license, and indicate if changes were made.

\section{REFERENCES}

1. Berlinski A, Chavez A. Albuterol delivery via metered dose inhaler in a spontaneously breathing pediatric tracheostomy model. Pediatr Pulmonol. 2013;48(10):1026-34.

2. Holt S, Heullit M, Berlinski A, Chavez A. Albuterol delivery via $\mathrm{MDI} /$ spacer in a spontaneously breathing pediatric tracheostomy model: does bagging improve drug delivery? Am J Respir Crit Care Med. 2011;183:A3383.

3. White CC, Crotwell DN, Shen S, Salyer J, Yung D, DiBlasi RM. Bronchodilator delivery during 
simulated pediatric noninvasive ventilation. Respir Care. 2013;58(9):1459-66.

4. Ari A, Restrepo RD. Aerosol delivery device selection for spontaneously breathing patients: 2012. Respir Care. 2012;57(4):613-26.

5. Berlinski A, Willis JR. Albuterol delivery by 4 different nebulizers placed in 4 different positions in a pediatric ventilator in vitro model. Respir Care. 2013;58(7):1124-33.

6. Sidler-Moix A-L, Di Paolo ER, Dolci U, Berger-Gryllaki M, Cotting J, Pannatier A. Physicochemical aspects and efficiency of albuterol nebulization: comparison of three aerosol types in an in vitro pediatric model. Respir Care. 2015;60(1):38-46.

7. Michotte J-B, Jossen E, Roeseler J, Liistro G, Reychler G. In vitro comparison of five nebulizers during noninvasive ventilation: analysis of inhaled and lost doses. J Aerosol Med Pulm Drug Deliv. 2014;27(6):430-40.

8. Ghazanfari T, Elhissi AM, Ding Z, Taylor KM. The influence of fluid physicochemical properties on vibrating-mesh nebulization. Int $\mathrm{J}$ Pharm. 2007;339(1):103-11.

9. Hassan A, Rabea H, Hussein RRS, Salah Eldin R, Abdelrahman MM, Said ASA, Salem HF, Abdelrahim ME. In-vitro characterization of the aerosolized dose during non-invasive automatic continuous positive airway pressure ventilation. Pulm Ther. 2016;2(1):115-26.

10. ElHansy MHE, Boules ME, Farid H, Chrystyn H, ElMaraghi SK, Al-Kholy MB, El-Essawy AFM, Abdelrahman MM, Said ASA, Hussein RRS, Rabea $H$, Abdelrahim MEA. In vitro aerodynamic characteristics of aerosol delivered from different inhalation methods in mechanical ventilation. Pharm Dev Technol. 2017;22(6):844-9.

11. Dhand R, Tobin MJ. Inhaled bronchodilator therapy in mechanically ventilated patients. Am J Respir Crit Care Med. 1997;156(1):3-10.

12. Parkes SN, Bersten AD. Aerosol kinetics and bronchodilator efficacy during continuous positive airway pressure delivered by face mask. Thorax. 1997;52(2):171-5.

13. Abdelrahim $M$, Plant $P$, Chrystyn $H$. The relative lung and systemic bioavailability of terbutaline following nebulisation in non-invasively ventilated patients. Int J Pharm. 2011;420(2):313-8.

14. Duarte AG. Inhaled bronchodilator administration during mechanical ventilation. Respir Care. 2004;49(6):623-34.
15. Hussein RRS, Ali AMA, Salem HF, Abdelrahman MM, Said ASA, Abdelrahim MEA. In vitro/in vivo correlation and modeling of emitted dose and lung deposition of inhaled salbutamol from metered dose inhalers with different types of spacers in noninvasively ventilated patients. Pharm Dev Technol. 2017;22(7):871-80.

16. Rabea H, Ali AMA, Salah Eldin R, Abdelrahman MM, Said ASA, Abdelrahim ME. Modelling of in vitro and in vivo performance of aerosol emitted from different vibrating mesh nebulisers in noninvasive ventilation circuit. Eur J Pharm Sci. 2017;97:182-91.

17. Abdelrahim ME, Plant $P$, Chrystyn H. In-vitro characterisation of the nebulised dose during noninvasive ventilation. J Pharm Pharmacol. 2010;62(8):966-72.

18. Ari A, Areabi H, Fink J. Evaluation of aerosol generator devices at 3 locations in humidified and nonhumidified circuits during adult mechanical ventilation. Respir Care. 2010;55(7):837-44.

19. Ari A, Atalay OT, Harwood R, Sheard MM, Aljamhan EA, Fink JB. Influence of nebulizer type, position, and bias flow on aerosol drug delivery in simulated pediatric and adult lung models during mechanical ventilation. Respir Care. 2010;55(7):845-51.

20. Hassan A, Salah Eldin R, Abdelrahman MM, Abdelrahim ME. In-vitro/in vivo comparison of inhaled salbutamol dose delivered by jet nebulizer, vibrating mesh nebulizer and metered dose inhaler with spacer during non-invasive ventilation. Exp Lung Res. 2017;43(1):19-28.

21. Ari A, Harwood RJ, Sheard MM, Fink JB. Pressurized metered-dose inhalers versus nebulizers in the treatment of mechanically ventilated subjects with artificial airways: an in vitro study. Respir Care. 2015;60(11):1570-4.

22. Chatmongkolchart S, Schettino GP, Dillman C, Kacmarek RM, Hess DR. In vitro evaluation of aerosol bronchodilator delivery during noninvasive positive pressure ventilation: effect of ventilator settings and nebulizer position. Crit Care Med. 2002;30(11):2515-9.

23. Calvert L, Jackson J, White J, Barry P, Kinnear W, O'callaghan C. Enhanced delivery of nebulised salbutamol during non-invasive ventilation. J Pharm Pharmacol. 2006;58(11):1553-7.

24. Moustafa IOF, ElHansy MHE, Al Hallag M, Fink JB, Dailey P, Rabea H, Abdelrahim MEA. Clinical outcome associated with the use of different inhalation method with and without humidification in 
asthmatic mechanically ventilated patients. Pulm Pharmacol Ther. 2017;45:40-6.

25. Saeed H, Mohsen M, Fink JB, Dailey P, Salah Eldin A, Abdelrahman MM, Elberry AA, Rabea H, Hussein RRS, Abdelrahim MEA. Fill volume, humidification and heat effects on aerosol delivery and fugitive emissions during noninvasive ventilation. J Drug Deliv Sci Technol. 2017;39:372-8.

26. Mohsen M, Elberry AE, Salah Eldin A, Hussein RR, Abdelrahim EM. Effects of heat and humidification on aerosol delivery during auto-CPAP noninvasive ventilation. Arch Pulmonol Respir Care. 2017;3(1):11-5.

27. Saeed H, Elberry AA, Eldin AS, Rabea H, Abdelrahim MEA. Effect of nebulizer designs on aerosol delivery during non-invasive mechanical ventilation: a modeling study of in vitro data. Pulm Ther. 2017;3(1):233-41.

28. Sarhan RM, Elberry AA, Abdelwahab NS, Rabea H, Salem MN, Abdelrahim MEA. Effect of a nebulizer holding chamber on aerosol delivery. Respir Care. 2018 (in press).

29. Lange CF, Finlay WH. Overcoming the adverse effect of humidity in aerosol delivery via pressurized metered-dose inhalers during mechanical ventilation. Am J Respir Crit Care Med. 2000;161(5):1614-8.

30. Moustafa IO, Ali MR-A, Al Hallag M, Rabea H, Fink JB, Dailey P, Abdelrahim ME. Lung deposition and systemic bioavailability of different aerosol devices with and without humidification in mechanically ventilated patients. Heart Lung J Acute Crit Care. 2017;46(6):464-7.

31. Saeed H, Ali AMA, Elberry AA, Salah Eldin A, Rabea $\mathrm{H}$, Abdelrahim MEA. Modeling and optimization of nebulizers' performance in non-invasive ventilation using different fill volumes: comparative study between vibrating mesh and jet nebulizers. Pulm Pharmacol Ther. 2018 (in press).

32. Saeed H, Mohsen M, Salah Eldin A, Elberry AA, Abdelwahab NS, Hussein RRS, Rabea H, Abdelrahim MEA. Effects of fill volume and humidification on aerosol delivery during single limb non-invasive ventilation. Respir Care. 2018 (in press).

33. Branson RD, Gentile MA. Is humidification always necessary during noninvasive ventilation in the hospital? Respir Care. 2010;55(2):209-16.

34. Lin H-L, Fink JB, Zhou Y, Cheng Y-S. Influence of moisture accumulation in inline spacer on delivery of aerosol using metered-dose inhaler during mechanical ventilation. Respir Care. 2009;54(10):1336-41.

35. Boukhettala N, Porée T, Diot P, Vecellio L. In vitro performance of spacers for aerosol delivery during adult mechanical ventilation. J Aerosol Med Pulm Drug Deliv. 2015;28(2):130-6.

36. Harb HS, Elberry AA, Rabea H, Fathy M, Abdelrahim MEA. Is Combihaler usable for aerosol delivery in single limb non-invasive mechanical ventilation? J Drug Deliv Sci Technol. 2017;40:28-34.

37. Chatila W, Nugent T, Vance G, Gaughan J, Criner GJ. The effects of high-flow vs low-flow oxygen on exercise in advanced obstructive airways disease. Chest. 2004;126(4):1108-15.

38. Ward JJ. High-flow oxygen administration by nasal cannula for adult and perinatal patients. Respir Care. 2013;58(1):98-122.

39. Marshall SG, Henry NR, Russian CJ. Right versus left prong nasal cannula flow delivery and the effects of nasal cycling on inspired $\mathrm{F}(\mathrm{IO} 2)$ in an adult anatomic model. Respir Care. 2016;61(4):397-404.

40. Zhang J, Lin L, Pan K, Zhou J, Huang X. High-flow nasal cannula therapy for adult patients. J Int Med Res. 2016;44:1200-11.

41. Braunlich J, Kohler M, Wirtz H. Nasal highflow improves ventilation in patients with COPD. Int J Chron Obstruct Pulm Dis. 2016;11:1077-85.

42. Tian G, Hindle M, Longest PW. Targeted lung delivery of nasally administered aerosols. Aerosol Sci Technol. 2014;48(4):434-49.

43. Perry SA, Kesser KC, Geller DE, Selhorst DM, Rendle $\mathrm{JK}$, Hertzog JH. Influences of cannula size and flow rate on aerosol drug delivery through the Vapotherm humidified high-flow nasal cannula system. Pediatr Crit Care Med. 2013;14(5):e250-6.

44. Ari A, Harwood R, Sheard M, Dailey P, Fink JB. In vitro comparison of heliox and oxygen in aerosol delivery using pediatric high flow nasal cannula. Pediatr Pulmonol. 2011;46(8):795-801.

45. Bhashyam AR, Wolf MT, Marcinkowski AL, Saville A, Thomas K, Carcillo JA, Corcoran TE. Aerosol delivery through nasal cannulas: an in vitro study. J Aerosol Med Pulm Drug Deliv. 2008;21(2):181-8.

46. Madney YM, Fathy M, Elberry AA, Rabea $H$, Abdelrahim MEA. Nebulizers and spacers for aerosol delivery through adult nasal cannula at low oxygen flow rate: an in vitro study. J Drug Deliv Sci Technol. 2017;39:260-5. 
47. Saeed H, Ali AMA, Elberry AA, Eldin AS, Rabea H, Abdelrahim MEA. Modeling and optimization of nebulizers' performance in non-invasive ventilation using different fill volumes: comparative study between vibrating mesh and jet nebulizers. Pulm Pharmacol Ther. 2018;50:62-71.
48. Harb HS, Elberry AA, Rabea H, Fathy M, Abdelrahim MEA. Performance of large spacer versus nebulizer T-piece in single limb non-invasive ventilation. Respir Care. 2018 (in press). 